does very well in avoiding local and specialised rocknames, though we suppose "kentallenite" (p. 89), the incorrect but accepted use of "granophyre" (p. 92), and "keratophyre" could scarcely be kept out. A large part of the book is naturally devoted to sedimentary rocks, and no reader will fail to appreciate their structure, and the interesting way in which structure records their modes of origin. The treatment of slate is an excellent example; we note that chemical composition is here so dominated by the compactness and by the fissile structure of the rock as to have no effect on relative durability (p. 287). Limestones are also adequately dealt with, the important oolitic stones of England being described in considerable detail. Among sandstones, we may direct attention to the interesting account of the Surrey "firestone" on p. 166. There is much in this book which will enable the professional geologist to give a "practical" touch to his teaching, and thus in turn to attract the technical student towards the broader aspects of geology. One of the chief rewards of the instructor in a modern college is to note the pleasure aroused when some familiar feature is explained. The "practical man" may know a good deal already about a stone, but he now sees it taking its place in the history of a world of stones.

Mr. Howe's chapter on the decay of building stone is especially to the point. He uses chemical symbols at times in his text in place of words, which is scarcely literary; but he shows well how sodium chloride and other salts increase the attack of rainwater on a stone, and how the acids liberated in towns also play their destructive part. A special section is devoted to the decay of limestones. The deleterious formation of gypsum in parts of buildings sheltered from the rain, or even beneath rain-washed surfaces, is impressively pointed out. Crystalline dolomites (p. 353) decay in the country through the more rapid solution of any calcite granules that are present, while in towns a worse evil befalls them, from the fact that magnesium sulphate is even more soluble than gypsum. The sulphuric acid in towns, of course, arises from the iron pyrites contained in coal. Mr. Howe's remarks as to our love for limestone (p. 9) should be taken to heart by architects.

There is a useful chapter on the testing of stones; but we question if the appendices which follow, containing lists of quarries, were worth compiling in view of the far more complete lists issued by the Home Office, and referred to on p. 435. A liberal description, however, not merely an enumeration, is given of the sandstones of Ireland (the heading accidentally calls them limestones). The reason for this treatment is not apparent, since a reference to the source of information, Kinahan's "Economic Geology of Ireland," would show that a similarly detailed essay might be written on any class of Irish stone.

It is one of the curses of curators that manuscript labels lead to cumulative errors in the names of places. Mr. Howe has succeeded far better than any copyist would have done. We do not know if his variations from Kinahan are accidents or corrections, for Kinahan was indifferent to proof-reading; but such words as Dundale, Geradmer, Blekinje, Thuringewald,
Böhm-Brod, and Maenturog require emendation. Why write "the Tyrol," and also "Steiermarls" and "Mähren"? But at such a book-the metaphor is obvious-we would not willingly cast a stone. We are additionally grateful for an index of twenty pages.

(2) Mr. John Watson's work represents an immense amount of patient application, behind which lies real enthusiasm. He has brought together a collection of building stones for the Sedgwick Museum in Cambridge, in which he aims at representing the whole world. He has presented a large number of the specimens, and furnishes a catalogue of rocks used in construction, leaving those used for decoration, roadmaking, and roofing for future work. On p. 8 he approves "a suggestion" that the University of Cambridge might be a fit place for "a national bureau, where building stone could be examined, tested, and reported on." The existence of the Geological Survey, of Great Britain, as a public body of the first standing, would no doubt occur to our legislators, and the difference of outlook adopted in an economic and in a university museum is at once seen by Mr. Watson's choice of a classification. His stratified building stones are arranged according to their geological age, and are then grouped under their countries of origin. It is a question if this appeals even to the university student of petrology, and it certainly conveys no useful information to the seeker after building stones. The admirable index of fifty pages, surpassing that of the diligent $\mathrm{Mr}$. Howe, does not set matters straight. There are thus twenty-six references to oolites, even though the Caen stone of p. I84 is omitted; but the seeker after sandstone will have to turn the pages of the volume. Granites, however, are copiously indexed as a group. The universities, having adopted law and medicine, have proceeded to engineering, mining, and distilling. It may now be too late to leave building construction and building stones to great technical colleges, of the type of the Royal School of Mines. Mr. Watson's book, issued at so very moderate a price, is a treasury of information for the inquirer. It is not the author's fault if it seems to emphasise that overlapping of functions which threatens to impoverish British centres of education.

G. A. J. C.

\section{SUPERNORMAL PSYCHOLOGY.}

(1) New Evidences in Psychical Research. A Record of Investigations, with Selected Examples of Recent S.P.R. Results. By J. Arthur Hill. With an introduction by Sir Oliver Lodge, F.R.S. Pp. xiit 2I8. (London: Wm. Rider and Son., Ltd., I9II.) Price $3 s, 6 d$. net.

(2) Personality and Telepathy. By F. C. Constable. Pp. $x v+330$. (London: Kegan Paul and Co., Ltd., IorI.) Price $7 s .6 d$. net.

T $T$ was in the early 'seventies of last century that 1 men of scientific training began to take an interest in certain mental and physical phenomena which appeared to transcend the ordinary laws of psychology and biology. It has taken a generation to acclimatise some of these phenomena in the realm of serious and orthodox scientific pursuit, and the two present NO. 2176 , VOL. 87$]$ 
volumes represent further, attempts, along two different lines, to win recognition for apparently supernormal facts, and to frame theories capable of bringing them into line with general knowledge.

Mr. Hill's book ( $\mathrm{I}$ ) is an eminently temperate and dispassionate statement and analysis of selected cases of clairvoyance and automatism, the former including the sayings of a professional clairvoyant, and the latter dealing with the "cross-correspondences," now fairly well known, between the automatic writings of Mesdames Thompson, Forbes, Holland, Verrall, and Piper. It is not difficult to perceive that the author inclines to the agency of disembodied human intelligences as the simplest explanation of many of the phenomena dealt with. When, in circumstances which exclude collusion as a reasonable hypothesis, phrases and allusions are simultaneously written out automatically by two or more persons in different continents, different phrases which only become intelligible on being pieced together, the case for assuming the operation of some intelligence different from that of the writers becomes strong. When, in addition, these phrases are characteristic of a Gurney, Myers, Sidgwick, or Hodgson, the temptation to attribute them to those deceased personalities is obvious. On the other hand, if telepathy and clairvoyance are real faculties, the proof of identity is faced with apparently insurmountable difficulties. Nevertheless, Mr. Hill's book is a valuable contribution to our knowledge of this difficult subject, and it is rendered particularly acceptable by the author's "careful and responsible truthfulness" and "unemotional habit of mind," to which Sir Oliver Lodge testifies in his introduction.

(2) Mr. Constable's book is an ambitious attempt to colligate the same range of facts by a new theory of personality. Experimental telepathy is assumed to be fully established, and is accounted for by the existence of an "intuitive self," which is in "timeless and spaceless" communion with all other intuitive selves. A large part of the book is taken up with a criticism of Kant and his transcendental dialectic, and the new departure claimed is the proof of the existence of the intuitive self from facts of ordinary human experience, chiefly relating to telepathy, or the reception of impressions otherwise than through the normal organs of sense.

The book as it stands can scarcely be said to succeed even in its main object, for even if telepathy were fully established, the possibility of some form of physical vehicle is becoming, if anything, increasingly obvious in these days of wireless transmission; and the whole conception of the "intuitive self" tends to remove these matters from all scientific procedure. An author who confesses his inability "to distinguish between time and space" (p. 34) is scarcely likely to convert physiologists or even psychologists to his views on crystal-gazing, or "psychometry," or communion with the disembodied. Any theory of survival likely to appeal to the scientific mind must be based upon physiological rather than metaphysical reasoning, and must, above all, remain in touch with the facts of racial and individual development. A physical scheme of inmortality cannot be ruled out as an a priori impossibility while so many unknown forms of matter NO. 2 I 76 , VOL. 87$]$ and energy remain to be discovered. Meanwhile, a transcendental self, independent of space and time, makes too great a demand on our powers of conception to be of any living scientific interest.

E. E. F.

\section{OUR BOOK SHELF,}

A Star Atlas and Telescopic Handbook (Epoch 1920). For Students and Amateurs. By Arthur P. Norton. Pp. $19+16$ star and 2 index maps. (London and Edinburgh: Gall and Inglis, I9Io.) Price 5. net. For the general use of amateur astronomers this is the best atlas and hancibook we have yet seen. The sixteen maps are printed exceptionally clearly, nnd, while not overcrowded, show more than 7,000 objests. Each map is about Io in. by 8 in., and is part of a lune, covering, exclusive of overlap, four hours of R.A., and $60^{\circ} \mathrm{N}$. or S. of declination. The atlas opens out flat, and shows two maps joined together at the equator, so that about one-fifth of the whole sky is seen at once. Meridians and parallels mark every hour of R.A., and every tenth degree of declination, while marginal divisions enable a position to be fixed to the nearest $5 \mathrm{~m}$. or $1^{\circ}$. The polar regions are shown on two pairs of maps.

In addition to these excellent maps there are a large number of tables and a quantity of letterpress giving practically all the information the amateur is likely to require for ordinary work. The list of star catalogues, astronomical abbreviations and symbols, and the notes on astronomical terms are to be confidently recommended for their lucidity and trustworthiness. Then there is a number of notes on the planets, comets, meteors, eclipses, \&c., which are very interesting, concise, and informative. The sun and moon are awarded rather fuller treatment, and $a$ useful sketch-map of the latter forms the frontispiece.

All this is good, but what will probably appeal more strongly to the average amateur possessing a telescope is the section devoted to hints. These are eminently practical, and the observer is told how to take care of and to use his instrument, how to get to know its constants and capabilities. Should he wish to determine the focal length of his objective or mirror, or of his eyepiece, or the diameter of the field, or should he wish to clean the different delicate parts or undertake special work, he is advised tersely how to do it.

Then preceding each pair of regions there are a few notes directing attention to any special telescopic objects found therein; double stars, variables, nebulæ, and star clusters are located, and their special characteristics briefly described.

The whole work suggests that the author undertools a congenial task; the result shows he did it well.

$$
\text { W. E. Rolston. }
$$

Triumphs and Wonders of Modern Chemistry. A Popular Treatise on Modern Chemistry and its Marvels, Written in Non-Technical Language for General Readers and Students. By Dr. G. Martin. Pp. $\mathrm{xx}+358$. (London: Sampson Low, Marston, and Co., Ltd., IgII.) Price 7s. 6d. net.

THE author of this book has sought to make chemistry attractive to readers untrained in the methods of science, by offering them an account of some of the most surprising achievements of modern practical chemistry, and of the most startling deductions from recent chemical and physical speculations. These two subjects alternate throughout the book, but their treatment is of unequal value. Such practical matters as the liquefaction of air, the preparation of oxygen, and 